\title{
Editorial
}

\section{Videoconferencing, the Information Superhighway and the second Défi Américain}

The article "The interworking of Internet and ISDN networks for multimedia conferencing" by Clayman et al. in this issue describes a videoconferencing research project showing how a conference may be held between users connected to these two different networks.

The article shows that it can be done with some degree of difficulty because of equipment incompatibilities, protocol differences between the Internet and the ISDN, and within-ISDN protocol incompatibilities. The difficulties are such that researchers are able to hold videoconferences, but unless this research results in a much greater ease of interconnection, videoconferences of this type will be well beyond anyone without specialised knowledge and access to special software and equipment.

There are a number of constraints which will impede the implementation on any Information Superhighway including the interconnection of existing disparate networks, agreement on standards, existing telecom regulatory conditions, the development of inexpensive easy-to-use television set top boxes for service selection and user interaction, copyright problems, supply of risk capital, uncertainty about information service needs and markets, the formation of appropriate alliances between competitive suppliers, and the changes required in present life-style and expenditure patterns.

The first two items in this formidable list particularly affect videoconferencing. Depending on your belief in two recent forecasts of a $\$ 2.3$ billion (Dataquest) or $\$ 7.5$ billion (Gartner) for the 1997 market (if you believe either of them), videoconferencing is about to take off. In the early eighties a rosy future was forecast for the Picturephone, a monumental flop. "There are many users and vendors who predict that teleconferencing will be as common in the office in 1990 as the typewriter is today", said Data Communications in 1982.

Internet and ISDN, and more particularly OSI and TCP/IP protocol incompatibility is of particular interest in Europe. A paper was published by the Directorate General Research of the European Parliament early in 1995 entitled Working Paper; W. 18; European Highways; which Standards? In spite of its origin it states, rather curiously, that the opinions expressed are "not in any way those of the European 
Parliament". It quotes an article from Le Monde Diplomatique entitled "Qui tirera profit des autoroutes de l'information?", the comment: "The concerns of the public are being disdainfully disregarded as greater support is given to the objectives of the giant cable, telephone and leisure companies".

It considers that Internet's TCP/IP protocol is "an essentially monocultural model" whereas OSI is "polyculturally inspired". Furthermore the paper concludes that "a specifically European Internet" should be developed "as a support for the Standards chosen by the Europeans. By allowing the other side to choose the playing field the European Union is obliged to leave everything to their initiative, to move forward at the pace they impose, to play on unequal terms, and ultimately to retreat on other fronts".

Having discussed the merits of OSI standards versus Internet's TCP/IP protocol, the paper considers that the market should be forced "to give up the immediate advantages of marketing the first available standard" ... and the EU should "develop a specifically European Internet as a support for the Standards chosen by the Europeans, both for equipment and for services (applications) by means of tax incentives ..."

It is unclear whether this is an "official viewpoint" or not. The probability that the EU could introduce measures to successfully defeat La deuxième défi Américain* seems remote. The lessons of history are clear. In market forces versus Governmental action contests, market forces usually win. In this case it may be unpalatable to some, but the market says "Internet with TCP/IP" please.

A.E. Cawkell

\footnotetext{
* Servan-Schreiber's book Le Défi Américain describes what he considers to be the decline of Europe in the face of an American economic invasion. Later, Nora and Minc presented a report to the President of France which prompted substantial changes in French policy.
} 